\title{
The treatment of head injury during the Renaissance
}

\author{
B Nathan, G Evans
}

During the Renaissance, a new spirit of rational inquiry, combined with renewed understanding of ancient Greek and Roman philosophy, encouraged many new developments in medicine and surgery. Traditional teachings, often combined with superstition and a belief in magical and empirical cures, had dominated medical thinking for over a thousand years; after the Renaissance, this ignorance was gradually replaced by fresh thought, based on logic, observation, and experiment. Surgeons, by nature practical men, whose daily work forced them to regard hard facts as more important than arcane theories, played an important role in this process, despite their comparatively low social status as "artisans" rather that academics. In this article we review the evidence regarding the performance of trepanning during the Renaissance. This operation had originally been used for superstitious or religious purposes, had fallen largely into disuse, but was then reintroduced in severe head injuries on a somewhat more rational basis.

Trepanning, or making a surgical hole in the skull, is known to have been performed since prehistoric time as a means of allowing unwanted spirits or vapours out of the head. As a treatment for head injury it was never popular among surgeons, in view of the great risks involved and the skill and instruments needed. A natural desire to avoid painful treatments if possible motivated the search for an alternative to surgery. Dino del Garbo (died 1327), a member of the Florentine guild of surgeons and physicians, noted that it was widely believed that skull fractures could be cured by the use of plasters alone without the surgical procedures recommended, in one form or another, by most authoritative textbooks. ${ }^{1}$ Dino attributed the belief in the efficacy of plasters used alone to the extreme willingness of the public to believe in such cures and to the ignorance or deceit of empirics. Dino was evidently well aware of the difficulty of diagnosing head wounds by palpation and observation and asserted that the empirics either could not themselves tell skull fractures from other head wounds or else inflated their own powers by claiming that any head wound they had cured was a skull fracture.

Furthermore literature on surgery and head wounds was scanty. With the exception of a few brief tracts on phlebotomy and sites for cautery, most of the medical handbooks available until the 11 th century had little or nothing to say about surgery that was not then distinguishable from the rest of medical practice. Greek surgery was largely inaccessible until the 15th and 16th centuries. The Hippocratic treatise On wounds of the head provided the principal source in the works of Celsus (first century AD), Galen (second century AD), and Paul of Aegina (seventh century AD). These were too long and complicated to be of any practical use to early medieval western practitioners. Hippocrates' emphasis was on how to reach an accurate prognosis to convey to the relatives and not direct surgical intervention. Hippocrates discusses which kinds of missiles produce torn flesh or broken bones, whether the missile came from above or from the side, and so on.

Francisco Arceo (1493-1571), a military Spanish surgeon whose treatise on wounds of the head was influential both in England and the rest of Europe, remarks on how the operation of trepanning is unpopular (the words in parentheses were added by the contemporary English translator):

"For how many are there in this hether part of Spaine, to whom the use of the trepan is knowen, (and if I might under correction demande the like question, I faine know unto how manie of our chirurgions in England is the use of this instrument knowen) yea, not onely the use of the trepan, but also the office of boxing or percing the skull is utterlie condemned of them as a thing most dangerous and deadlie." 2

It therefore seems that only a handful of surgeons whose publications have made them famous embarked on this operation.

The mechanism of closed head injury with intracranial haemorrhage but without an apparent external wound was not understood and hence trepanning was usually performed on patients with scalp lacerations or penetrating injuries. Patients with suspected skull fractures but no external cuts posed a diagnostic challenge and Ambroise Paré (1510-90), the great renaissance French surgeon, recommended exploring the overlying scalp in order to examine the underlying bone: 


\section{Chenobleexperpente of the betuous} banov1batkeof furgetipzactp[vos conrppleoby thenooft eqpecte mays

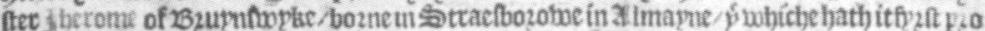

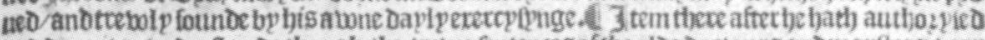
and Done it to bnoctetanoe th)ugh the trewe feitences ofthe oloe Doctouts anomaytets very

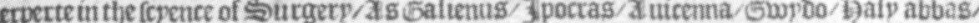

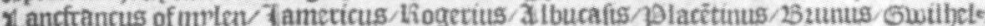
mus oe faliceto/a by many otheruayfters whofe names be wotyten in this fanc bote. ( l)cte

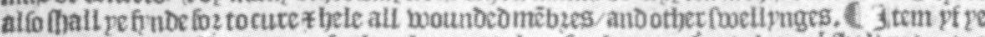

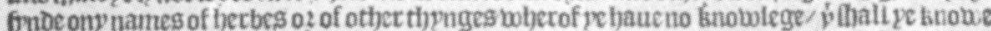

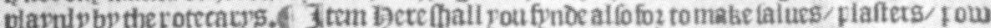

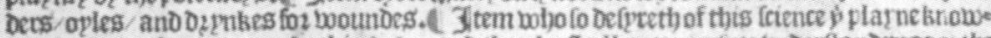

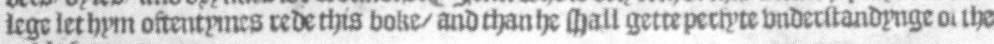
noble furgerp.

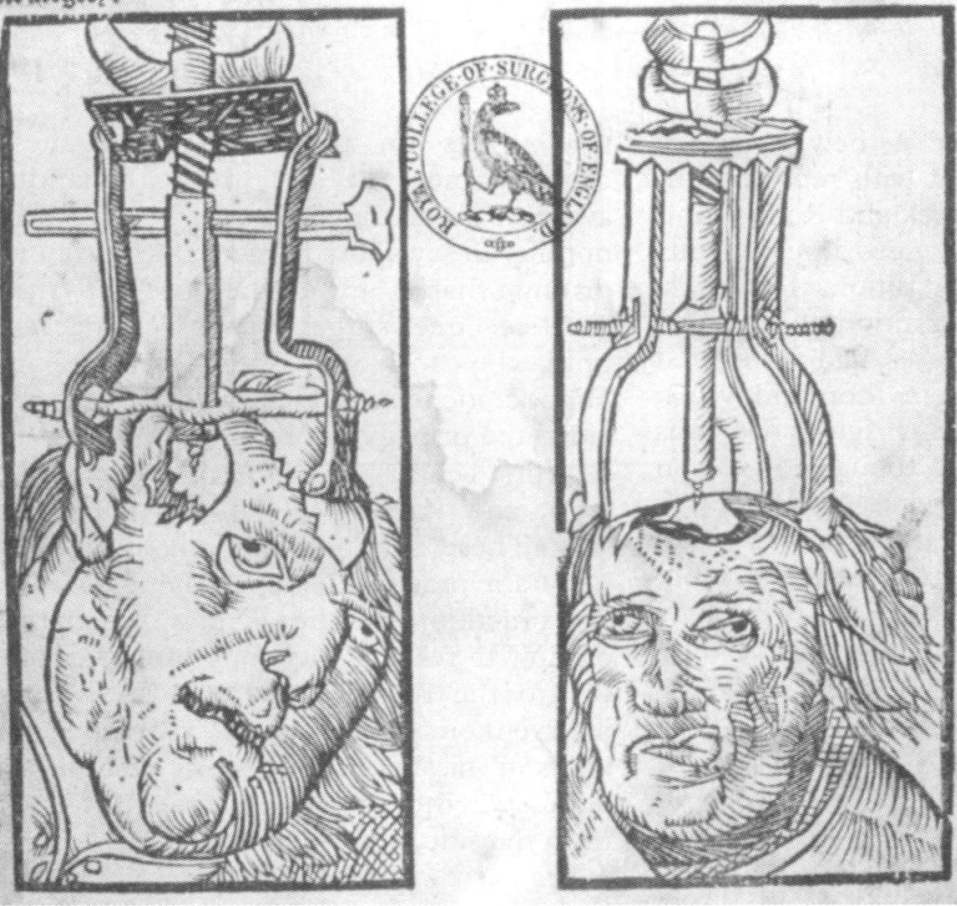

Figure 1 Title page of the 1525 London edition of Brunschwig's Noble experience of surgery. (Reproduced by kind permission of the President and Council of the Royal College of Surgeons of England.)
"If upon great contusion the scull bee depressed like the print of a bruse in a brasse or pewter pot you must make incision to the bone, and fasten upon it a whimble or piercer with a screw, and therewith draw the bone upward."

The operation of trepanning was not performed as an emergency but rather electively a few days after the head injury, during which period the patient would have been nursed in a dark quiet room until the surgeon had been summoned, often from another town. It also seems unlikely that trepanning was performed on unconscious patients. This practice served to eliminate all immediately fatal injuries. Francisco Arceo says:

"The third day after the wound is made, it shal be expedient to use the office of the trepan or percer."

An impressive array of instruments was available for this work that were not readily available and had to be made to order, according to designs and patterns provided by the surgeon. Jerome of Brunschwig (c1450-1533), author of the first surgical textbook to be printed in England (fig 1), listed five basic tools-the trepan, a bone lever, a chisel, a rugine, and a hammer. ${ }^{6}$

After trepanning, Paré advised draining the cranial cavity with a lead tube using a Valsalvatype manoeuvre to improve drainage:

"Put into the wound a smooth pipe of lead; every dressing commanding the patient to stop his nostrils, and to expire with all his strength, holding the head downeward; so by that pipe much matter came away, which was collected betwixt the scull and the meninx."”

Unfortunately, the results of treatment were not given by any of the authors but this did not seem to have deterred these dedicated and brave surgeons from embarking upon what we regard as major neurosurgery in a genuine attempt to save the lives of their patients.

1 Siraisi NG. Surgeons and surgery. In: Medieval and early renaissance medicine. Chicago: University of Chicago Press, 1990.

2 Arcaeus F. A most excellent method of curing wounds, 1588 : chapter 3.

3 Paré A. An explanation of instruments, 1634:35-40.

4 Paré A. An explanation of instruments, 1634:41.

5 Arcaeus F. $A$ most excellent method of curing wounds, 1588: chapter 4.

6 von Brunschwig $\mathrm{H}$. The noble experience of surgeri. Southwarke, 1525: chapter 36.

7 Paré A. An explanation of instruments, 1634:62. 